Research Paper

\title{
Berberine Enhances Chemosensitivity and Induces Apoptosis Through Dose-orchestrated AMPK Signaling in Breast Cancer
}

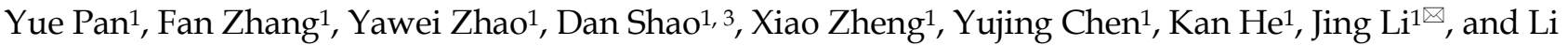 \\ Chen $^{1,2}{ }^{\square}$ \\ 1. Department of Pharmacology, College of Basic Medical Sciences, Jilin University, Changchun 130021, China; \\ 2. School of Nursing, Jilin University, Changchun 130020, China; \\ 3. Department of Biomedical Engineering, Columbia University, New York, NY 10027, USA. \\ $\square$ Corresponding authors: Dr. Jing Li, Department of Pharmacology, Basic College of Medicine, Jilin University, 126 Xinmin Street, Changchun 130021, People's \\ Republic of China; telephone/fax: +86 431 85619799; e-mail: lijing@jlu.edu.cn (J. Li) Dr. Li Chen, Department of Pharmacology, Basic College of Medicine, Jilin \\ University, 126 Xinmin Street, Changchun 130021, People's Republic of China; telephone/fax: +86 431 85619366; e-mail: chenl@jlu.edu.cn (L. Chen). \\ (c) Ivyspring International Publisher. This is an open access article distributed under the terms of the Creative Commons Attribution (CC BY-NC) license \\ (https:// creativecommons.org/licenses/by-nc/4.0/). See http://ivyspring.com/terms for full terms and conditions.
}

Received: 2017.01.08; Accepted: 2017.04.07; Published: 2017.06.05

\begin{abstract}
Breast cancer is the most common malignancy in women. Although personalized or targeting molecular cancer therapy is more popular up to now, the cytotoxicity chemotherapy for patients with advanced breast cancer is considered as the alternative option. However, chemoresistance is still the common and critical limitation for breast cancer treatment. Berberine, known as AMPK activator, has shown multiple activities including antitumor effect. In this study, we investigate the chemosensitive effect of different dosages berberine on drug-resistant human breast cancer MCF-7/MDR cell in vitro and in vivo, and the mechanisms underlying AMPK activation on Doxorubicin (DOX) chemosensitivity. Our results showed that berberine could overcome DOX resistance in dose-orchestrated manner: On one hand, low-dose berberine can enhance DOX sensitivity in drug-resistance breast cancer cells through AMPK-HIF-1a-P-gP pathway. On the other hand, high-dose berberine alone directly induces apoptosis through the AMPK-p53 pathway with the independence of HIF-la expression. Taken together, our findings demonstrate that berberine sensitizes drug-resistant breast cancer to DOX chemotherapy and directly induces apoptosis through the dose-orchestrated AMPK signaling pathway in vitro and in vivo. Berberine appears to be a promising chemosensitizer and chemotherapeutic drug for breast cancer treatment.
\end{abstract}

Key words: berberine, breast cancer resistance, AMPK, HIF-1a, p53.

\section{Introduction}

Breast cancer is the most common malignancy in women, accounting for $31 \%$ of all female cancers around the world [1]. Although chemotherapy is effective in reducing the size of the primary tumor before surgery, long-term chemotherapy not only caused adverse effects in about half of breast cancer patients, but also inevitably induced multi-drug resistance [2]. A growing amount of evidence suggests that the extrusion of drugs by cell membrane pumps, apoptosis resistance, modification of drug-targeting molecules and drugs redistribution of the intracellular accumulation play crucial roles on chemotherapeutic resistance [1, 3]. However, the molecular mechanisms underlying the multidrug resistance of breast cancer are still ill-defined. Therefore, a better understanding of the chemoresistance is of great importance to develop novel therapeutic strategies for improving the poor prognosis.

Reprogramming cellular energy metabolism is 
recently accepted to be one of the main hallmarks of cancer [4]. Cancer cells, especially drug-resistant cancer cells, unlike their normal counterparts, employ exacerbated aerobic glycolysis rather than mitochondrial oxidative phosphorylation for maintaining their energy homeostasis, which called the 'Warburg effect' $[5,6]$. It has been suggested that the characteristic of energy metabolism shift facilitates cancer cell survival and contributes the drug resistance to conventional cancer chemotherapy and radiotherapy $[7,8]$. AMPK is a prominent sensor of cellular energy and AMPK activation reverse Warburg effect from aerobic glycolysis to oxidative phosphorylation, resulting in overcoming multidrug resistance [9]. Up to date, more research showed P-glycoprotein (P-gp) overexpression and apoptotic resistance associated with the activation of cell growth signaling pathway, including PI3K-AKT, PTEN, MAPK, ERK and p53 signaling pathway are closely related multidrug resistance. This two aspects both could be induced by the Warburg effect $[10,11]$. It has been reported that AMPK activation inhibits HIF-1a-mediated up-regulation of P-gp expression in a variety of human tumors [12]. AMPK activation can directly or indirectly inhibit tumor growth by blocking PI3K-AKT, MAPK, or Sirt1 cell growth signaling pathway $[13,14]$.

Berberine (BER), an isoquinoline alkaloid purified from the Berberis species, has exhibited multiple pharmacological activities, including antibacterial, anti-hypertensive, and anti-arrhythmic effects [15]. It has also been reported that low doses of berberine enhance radiosensitivity in colon cancer by inhibiting P-gp expression, while high doses of berberine can directly inhibit tumor growth in lung cancer through activating p53 [16-18], but there are few reports about whether berberine could enhance chemotherapy sensitivity and relative molecular mechanisms.

In this study, we firstly investigate whether dose-orchestrated berberine enhances DOX sensitivity in multidrug-resistant MCF-7/MDR human breast cancer cell, and then reveal the molecular mechanisms of berberine sensitilizing DOX in breast cancer in vitro and in vivo, which would shed light on the prevention and treatment of multidrug- resistant cancers.

\section{Materials and Methods}

\section{Chemicals and reagents}

Sulforhodamine B and Compound C were purchased from Sigma Aldrich. IOX2 was purchased from Selleckchem. DMEM high-glucose medium, foetal bovine serum (FBS), penicillin, streptomycin and BCA protein assay kits were purchased from the
Beyotime Institute of Biotechnology (Jiangsu, China). The primary antibodies were diluted 1:1000 before use, including AMPK (Cat. \# sc-25792, Santa Cruz Biotechnologies), p-AMPK (Cat. \# sc-33524, Santa Cruz Biotechnologies), HIF-1a (Cat. \#113642 Abcam), P-gp (Cat. \# sc-55510, Santa Cruz Biotechnologies), p53 (Cat. \# 10442-1-AP, Proteintech), Bax (Cat. \# sc-7480, Santa Cruz Biotechnologies), Cytochrome c (Cat. \# sc-13561, Santa Cruz Biotechnologies), Caspase 9 (Cat. \# 842, Cell signaling), Caspase 3 (Cat. \# 836, Cell signaling), PARP (Cat. \# 1442, Cell signaling) and GAPDH (Cat. \# sc-25778, Santa Cruz Biotechnologies). All the chemical compounds were analytically pure reagents.

\section{Cell culture and SRB assay}

Human breast cancer MCF-7 and multidrug-resistant MCF-7/MDR human breast cancer MCF-7/MDR cells were maintained in DMEM high-glucose medium supplemented with $10 \%$ foetal bovine serum (FBS), 100 units/mL penicillin, and 100 $\mu \mathrm{g} / \mathrm{mL}$ streptomycin in an atmosphere of $95 \%$ air and $5 \% \mathrm{CO} 2$ at $37^{\circ} \mathrm{C}$. MCF-7/MDR cells were purchased from Central South University. An SRB assay used to assess cell viability was performed in a 96-well plate in octuplicate. Cells were seeded at a density of $5 \times 10^{3}$ cells/well overnight and treated with berberine at final concentrations of $0,2.5,5,10,20,40,80,160$ and $320 \mu \mathrm{mol} / \mathrm{L}$, and/or $0.8 \mu \mathrm{mol} / \mathrm{L}$ Compound C, and/or $12.5 \mu \mathrm{mol} / \mathrm{L}$ IOX2 were added for $48 \mathrm{~h}$. Cells were seeded at a density of $5 \times 10^{3}$ cells/well overnight and treated with DOX at final concentrations of 0 , $0.31,0.63,1.25,2.5,5,10,20$ and $40 \mu \mathrm{g} / \mathrm{mL}$ with 5,10 , $20 \mu \mathrm{mol} / \mathrm{L}$ berberine, and/or $0.8 \mu \mathrm{mol} / \mathrm{L}$ Compound $\mathrm{C}$, and/or $12.5 \mu \mathrm{mol} / \mathrm{L}$ IOX2 were added for $48 \mathrm{~h}$. The cells were fixed with $10 \%$ trichloroacetic acid, and $0.4 \%(\mathrm{w} / \mathrm{v})$ SRB in $1 \%$ acetic acid was added to stain the cells. Unbound SRB was washed away with $1 \%$ acetic acid, and SRB-bound cells were rendered soluble with $10 \mathrm{mM}$ Tris-base $(\mathrm{pH}$ 10.5; Sigma Aldrich). The absorbance was read at a wavelength of $570 \mathrm{~nm}$.

\section{Apoptosis detection by flow cytometry}

Cell death and apoptosis were detected with an Annexin V-FITC Apoptotic Detection Kit by flow cytometry. In brief, after treating with 0,10 , and $80 \mu \mathrm{M}$ berberine for $48 \mathrm{~h}, \mathrm{MCF}-7 / \mathrm{MDR}$ cells were harvested and washed twice with cold PBS. Then, the cell pellets were resuspended with binding buffer to cell suspension at a density of $1 \times 10^{6}$ cells $/ \mathrm{mL}$.Next, $5 \mu \mathrm{L}$ of FITC-conjugated annexin $\mathrm{V}$ was added to the suspension and incubation was made for $15 \mathrm{~min}$ at $4^{\circ} \mathrm{C}$ in the dark. After that, $5 \mu \mathrm{L}$ of propidium iodide (PI) was injected into the mixture and incubated with 
cells for $5 \mathrm{~min}$. The samples were subsequently analysed by flow cytometry with an FACS Calibur flow cytometer (BD Biosciences, San Jose, CA, USA). The excitation wavelength was $488 \mathrm{~nm}$, the emission of FITC-conjugated annexin V was $515 \mathrm{~nm}$ and the propidium iodide (PI) emission was $560 \mathrm{~nm}$.

\section{Western blot analysis}

Cells washed twice with cold PBS and the cell pellets were suspended in $200 \mu \mathrm{L}$ RIPA lysis buffer for $30 \mathrm{~min}$ at $4^{\circ} \mathrm{C}$, vortexed every $10 \mathrm{~min}$, and then centrifuged at $12,000 \times \mathrm{g}$ for $15 \mathrm{~min}$. The supernatants containing the total protein extracts were collected. In some experiments, cytoplasmic protein extract was collected by a cytoplasmic protein extraction kit according to the manufacturer's protocols (Nan Jing Jian Cheng Bioengineering Institute Cat. \# E093).Tumor tissues from the five groups $(50 \mathrm{mg})$ were homogenized on ice at setting 8 for $2 \pm 30 \mathrm{~s}$ with a30-s interval using a Polytron PT 3000 tissue homogenizer (Brinkmann Instruments), in $1 \mathrm{ml}$ of buffer containing $10 \mathrm{mM}$ Tris- $\mathrm{HCl}, 0.25 \mathrm{M}$ sucrose, 10 $\mathrm{mM} \mathrm{NaCl}, 1 \mathrm{mM}$ EDTA, 1\% SDS and protease inhibitor cocktail (Roche), $\mathrm{pH}$ 7.5. The suspension was centrifuged at $3000 \mathrm{~g}$ for $15 \mathrm{~min}$ in an ultracentrifuge (Thermo Company). The supernatant was collected and then centrifuged at $12,000 \mathrm{~g}$ for $15 \mathrm{~min}$. The supernatant obtained was labelled as total protein extract. Protein concentration was measured by the Bradford Protein Assay Kit.

The immunoblotting analysis was performed with $20 \mathrm{\mu g}$ sample proteins on a $12 \%$ SDS-polyacrylamide electrophoresis gel (SDS-PAGE). The electrophoresis was carried out first at $80 \mathrm{~V}$ for $20 \mathrm{~min}$ and followed by $180 \mathrm{~V}$ for $60-85$ min. The separated proteins using SDS-PAGE gel were transferred to PVDF. The transferred membranes were incubated for $2 \mathrm{~h}$ in blocking buffer, TBST $(10 \mathrm{mM}$ Tris- $\mathrm{HCl}, 150 \mathrm{mM} \mathrm{NaCl}$ and $0.1 \%$ Tween-20) containing 5\% non-fat milk powder and then incubated overnight with primary antibody (1:800 or 1:1000) in $10 \mathrm{ml}$ TBST with gentle agitation at $4^{\circ} \mathrm{C}$. The membranes were then washed and incubated with the second antibody (1:2000) at room temperature for $1 \mathrm{~h}$. Bands were visualized by an ECL Western Blotting Detection System (Tanon 4200).

\section{Subcutaneous transplanted tumor model evaluation in nude mice}

Animal experiment protocols were approved by the Ethics Committee for the Use of Experimental Animals of Jilin University. MCF-7/MDR cells $(2 \times$ $10^{5}$ ) were collected in $70 \mu \mathrm{L}$ PBS and mixed with $70 \mu \mathrm{L}$ Matrigel Matrix (Becton Dickinson Biosciences). The mixture was injected subcutaneously on one side of the dorsal flank of 8-week-old female BALB/c nu/nu mice (Vital River Laboratories, Beijing, China). When tumor volume reached $60 \sim 100 \mathrm{~mm}^{3}$, mice were randomized into 5 groups $(n=6)$. The mice in control group treated with saline injected by tail vein every 3 days, the DOX group treated with DOX $\left(1 \mathrm{mg} \mathrm{kg}^{-1}\right)$ by tail vein injection every 3 days, the low dose berberine (Ber-L) group treated with berberine $\left(5 \mathrm{mg} \mathrm{kg}^{-1}\right)$ daily by oral gavage, the low dose berberine combined with DOX group (Ber-L+DOX) treated with berberine (5 $\left.\mathrm{mg} \cdot \mathrm{kg}^{-1}\right)$ daily by oral gavage and DOX $\left(1 \mathrm{mg} \mathrm{kg}{ }^{-1}\right)$ by tail vein injection every 3 days, the high dose berberine group treated with berberine $\left(200 \mathrm{mg} \mathrm{kg}^{-1}\right)$ daily by oral gavage. The body weights and tumor sizes were accurately recorded once every 3 days, and the tumor volume was calculated according to the formula: length $\times$ width $^{2} \times 0.52$. The mice were sacrificed 26 days after having been given the drugs. The tumors were isolated and immediately stored at $-80^{\circ} \mathrm{C}$ for later analysis.

\section{Statistical analysis}

All data were expressed as the mean \pm SD. Significance among groups wasanalysed by one-way analysis of variance (ANOVA), followed by Dunnett's multiple comparison post-test. A value with $\mathrm{p}<0.05$ was considered significant.

\section{Results}

\section{Cytotoxicity effect of high dose berberine on MCF-7/MDR cells}

To assess cytotoxicity profile of berberine on MCF-7/MDR cells, a series of concentrations of berberine (from $2.5 \sim 320 \mu \mathrm{M}$ ) was used to treat MCF-7/MDR cells for $24 \mathrm{~h}, 48 \mathrm{~h}$ and $72 \mathrm{~h}$. The cell viability was determined by SRB assay. As shown in Fig. 1, berberine has negligible influence on cell growth when the concentration is less than $20 \mu \mathrm{M}$. However, when the concentration is more than $40 \mu \mathrm{M}$, berberine inhibits MCF-7/MDR cell growth in a timeand dose-dependent manner, and then apoptosis of MCF-7/MDR cell treated with10 $\mu \mathrm{M}$ and $80 \mu \mathrm{M}$ berberine for $48 \mathrm{~h}$ was determined by flow cytometry, as shown in Fig. 1B, early apoptotic rate (Q4:2.2 \pm $0.64 \%$ vs. $2.24 \pm 0.82 \%$ ) and late apoptotic or necrotic rate(Q2: $3.48 \pm 0.95 \%$ vs. $3.51 \pm 0.91 \%)$ in $10 \mu \mathrm{M}$ berberine have no significant difference compared with control group, but in $80 \mu \mathrm{M}$ berberine treatment group, the early apoptotic cells are $31.59 \pm 5.41 \%$, the late apoptotic or necrotic cell are $10.01 \pm 2.13 \%$, indicating that high dose berberine $(80 \mu \mathrm{M})$ can cause MCF-7/MDR cells apoptosis. According to these results, we tried to detect whether low dose berberine 
(less than $20 \mu \mathrm{M}$ ) could increase chemosensitivity of DOX.

\section{Low-dose berberine enhances DOX chemotherapy sensitivity of MCF-7/MDR cell lines}

To confirm the difference of DOX chemotherapy sensitivity between MCF-7 and MCF-7/MDR cell lines, MCF-7 and MCF-7/MDR cells were exposed to the various concentrations of DOX $(0.04 \sim 5 \mu \mathrm{g} / \mathrm{mL})$ for $48 \mathrm{~h}$. Compared with MCF-7 cells, MCF-7/MDR cell becomes insensitive from the dosage higher than $0.16 \mathrm{\mu g} / \mathrm{mL}$ (Fig. 2A). Therefore, we treated MCF-7/MDR cells with DOX (concentrations from 0.31 to $40 \mu \mathrm{g} / \mathrm{mL}$ ) for $24 \mathrm{~h}, 48 \mathrm{~h}$ and $72 \mathrm{~h}$ combined with low concentrations of berberine $(5 \mu \mathrm{M}, 10 \mu \mathrm{M}$ and $20 \mu \mathrm{M})$ to investigate the effects of berberine-mediated sensitizing of DOX cytotoxicity. As shown in Fig. 2B-D, berberine with the concentrations from $10 \mu \mathrm{M}$ to $20 \mu \mathrm{M}$ significantly improves DOX sensitivity on MCF-7/MDR cells, especially after $48 \mathrm{~h}$ treatment. Giving that a $20 \mu \mathrm{M}$ berberine alone has negligible effect on cell growth of MCF-7/MDR cells (Fig. 1), it indicates that low-dose berberine could enhance the DOX chemotherapy sensitivity of MCF-7/MDR cell lines.

\section{Low-dose berberine suppresses P-gp by regulating the AMPK-HIF-1 $\alpha$ signaling pathway}

To discuss the mechanism of low dose berberine overcoming DOX resistance on MCF-7/MDR cells, we firstly investigated AMPK signaling pathway. It is found that low-dose berberine $(10 \mu \mathrm{M})$ can activate AMPK and reduce HIF-1a and P-gp expression (Fig. 3). To explore the downstream of AMPK signaling, AMPK inhibitor (Compound C) and HIF-1a stabilizer IOX2 was used. As indicated in Fig. 4A, low-dose berberine $(10 \mu \mathrm{M})$ combined with DOX strongly inhibits MCF-7/MDR cell growth, however, in the presence of Compound $\mathrm{C}$, the inhibition is significantly diminished compared with the same concentration of the berberine plus DOX co-treatment. As shown in Fig. 4C, Compound $\mathrm{C}$ alone do not affect HIF-1a and P-gp expression, but Compound C blocks low-dose berberine-induced AMPK phosphorylation, and berberine-induced the inhibition of HIF-1a and P-gp expression is prevented by Compound C, indicating that HIF-1a and P-gp are the downstream of AMPK.

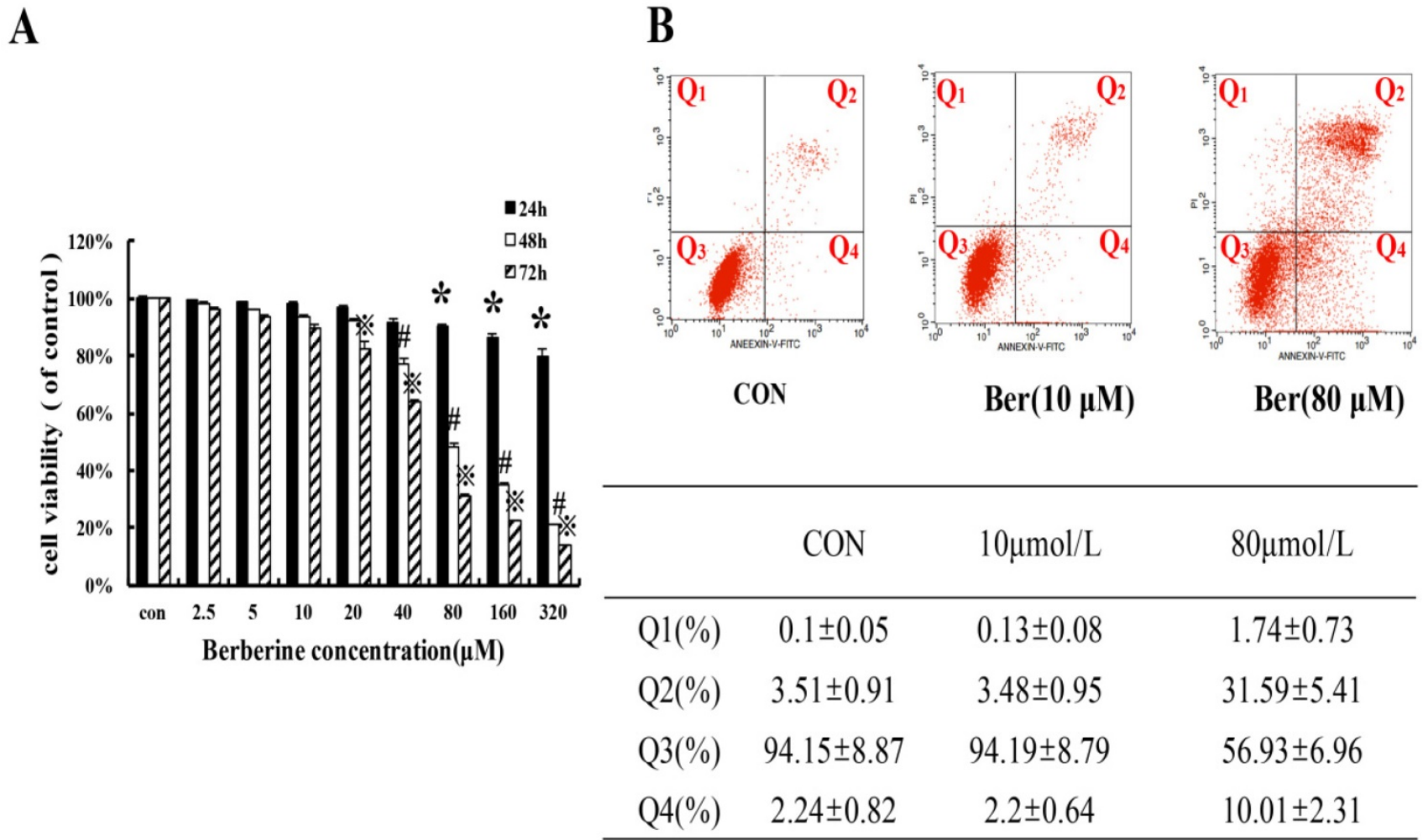

Figure 1. The cytotoxicity effect in MCF-7/MDR cells caused by berberine (A) The cell viability in MCF-7/MDR caused by berberine for $24 \mathrm{~h}, 48 \mathrm{~h}$ and $72 \mathrm{~h}$. Mean values $\pm S D, * P<0.05$, cells treated with different concentrations of berberine for $24 \mathrm{~h}$ vs. control group. \# $P<0.05$, cells treated with different concentrations of berberine for $48 \mathrm{~h}$ vs. control group. $※ \mathrm{P}<0.05$, cells treated with different concentrations of berberine for $72 \mathrm{~h}$ vs. control group. (B) The apoptosis rate in MCF-7/MDR caused by 0,10 and $80 \mu \mathrm{M}$ berberine for $48 \mathrm{~h}$. 

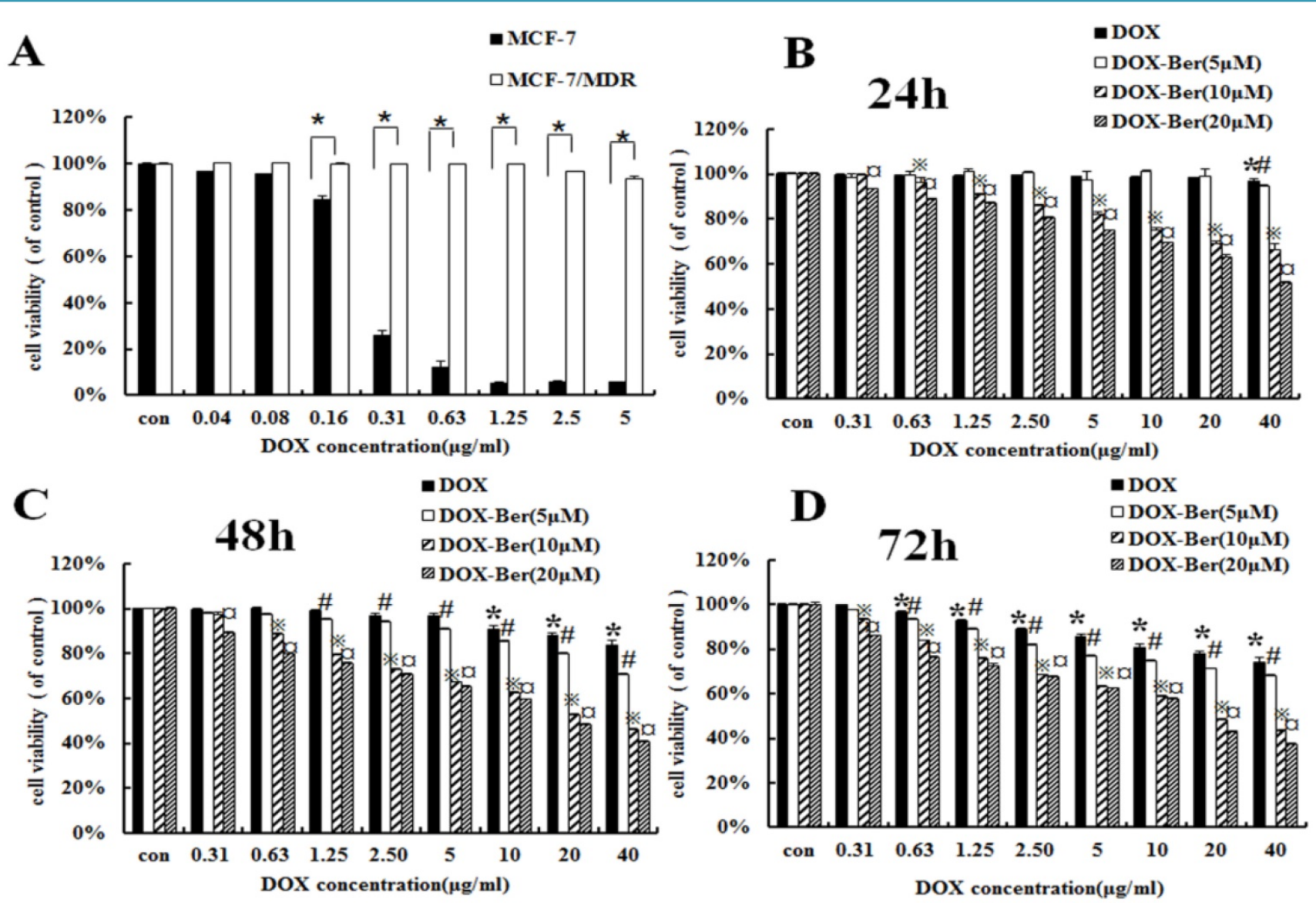

Figure 2. Berberine enhanced DOX sensitivity on MCF-7/MDR cells. (A) Cell viability of MCF-7 and MCF-7/MDR cells after DOX treatment for $48 \mathrm{~h}$ 。 $\mathrm{P}<0.05$, MCF-7 cell group vs. MCF-7/MDR cell group. (B-D) Effect of DOX combined with berberine in MCF-7 and MCF-7/MDR cells for $24 \mathrm{~h}, 48 \mathrm{~h}$ and $72 \mathrm{~h}$ treatment. Mean values $\pm S D, * P<0.05$, cells treated with different concentrations of DOX vs. control group. \# $P<0.05$, cells treated with different concentrations of $D O X$ and $5 \mu M$ berberine, compared with control group. $※ P<0.05$, cells treated with different concentrations of DOX and $10 \mu M$ berberine vs. control group. a $P<0.05$, cells treated with different concentrations of DOX and $20 \mu \mathrm{M}$ berberine vs. control group.

To further explore the relationship between HIF-1a and P-gp, HIF-1a stabilizer IOX2 was used. IOX2 can stabilize HIF-1a by selectively inhibiting prolyl-4-hydroxylase-2 (PHD-2), which can covalently modify two proline residues in the oxygen-dependent degradation (ODD) domain of HIF-1a subunits to promote HIF-1a degradation [19]. The increase of DOX chemosensitivity induced by berberine in MCF-7/MDR cells is weaken by the addition of IOX2 together with up-regulation of P-gp protein expression, and at the same time, the p-AMPK expression do not change at all (Fig. 5A and 5C). Our result reveals HIF-1a is a downstream protein of the AMPK and regulates the expression of P-gp.

Moreover, the mitochondrial apoptosis related protein Bax, Cytochrome C cleaved-Caspase 9, cleaved-Caspase 3 and cleaved-PARP do not changed after $10 \mu \mathrm{M}$ berberine alone treatment (Fig. 3), suggesting the mitochondrial apoptosis is not involved in the mechanism of DOX chemosensitivity of low dose berberine. In summary, It is demonstrated that low-dose berberine increases DOX chemosensitivity by activation of AMPK, subsequently downregulation of HIF-1a and P-gp expression.

\section{High-dose berberine induces apoptosis by activating the AMPK-p53 pathway with the independence of HIF-1 $\alpha$}

It is showed that high-dose berberine $(80 \mu \mathrm{M})$ can directly induce apoptosis in MCF-7/MDR cells (Fig.1). Cytotoxicity of berberine (more than $80 \mu \mathrm{M}$ ) is significantly decreased by AMPK inhibitor Compound C (Fig.4B), but IOX2 do not affect cell viability at the same dosage of berberine (Fig.5B). Western blot shows that $80 \mu \mathrm{M}$ berberine also up-regulates phosphorylated AMPK together with the reduction of HIF-1a, but we notice that the decrease of HIF-1a in high-dose berberine treatment is not more than that of low dose berberine (Fig.3). It is suggested the activation of AMPK is the key event for apoptosis induced by high dose berberine. 


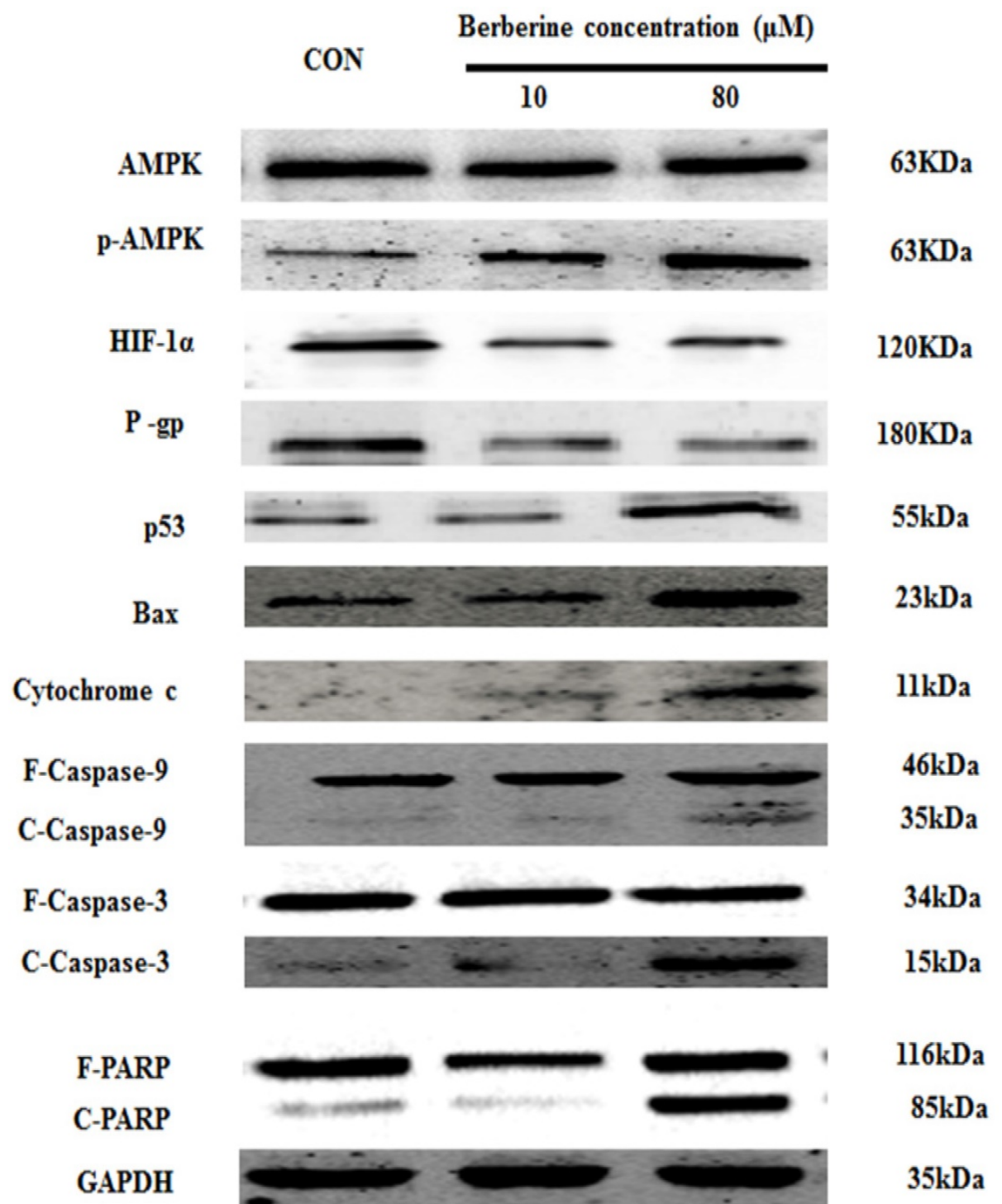

Figure 3. AMPK, p-AMPK, HIF-1 a, P-gp, p53, Bax, cytochrome c, Caspase 9, Caspase 3 and PARP protein expression by different concentrations of berberine treatment for $48 \mathrm{~h}$. Each result was repeated three times.

Interestingly, the levels of p53 is significantly increased in high-dose berberine treatment and the p53 up-regulation induces the activation of mitochondrial apoptosis pathway with the increase of Bax, the release of cytochrome c, cleaved-Caspase-9, cleaved-Caspase- 3 and cleaved PARP, compared with low-dose berberine treatment (Fig.3). p53 expression is remarkably reversed by AMPK inhibitor Compound C (Fig. 4C), indicating p53 is the main downstream of AMPK.

HIF-1a expression displays no dose-dependent manner whether in berberine alone or berberine combined with compound C (Fig.4C), indicating that HIF-1a activity is not essential for high-dose berberine-induced apoptosis in MCF-7/MDR cell lines. Moreover, IOX2 do not affect the expression of p53 in $80 \mu \mathrm{M}$ berberine treatment (Fig.5C). Consequently, high-dose berberine induces apoptosis by activating the AMPK-p53 pathway with the independence of HIF-1a.

\section{Berberine overcomes drug resistance in vivo}

The mice transplanted tumor model was used to evaluate berberine overcoming DOX resistance in MCF-7/MDR breast cancer. Five groups were set up as Con, DOX, low-dose berberine (Ber-L), low-dose berberine combined with DOX (Ber-L+DOX) and high-dose berberine (Ber-H). Fig. 6A-C shows that tumor volumes and weights are significantly reduced in the DOX, Ber-L+DOX and Ber-H group comparing with control group, Ber-L alone group has no difference with control group and there has significant difference between Ber-L+DOX with either of Ber-L or DOX alone group, indicating that berberine increases the cytotoxicity of DOX in vivo.

Moreover, we detected the relative protein in 
AMPK signaling pathway in MCF-7/MDR xenograft. As shown in Fig. 7, low-dose berberine significantly induces the activation of AMPK and inhibits the expression of HIF and P-gp, while high-dose berberine promotes the expression of p53 by activating AMPK, which are consistent with the result in vitro.

\section{Discussion}

Acquired resistance to standard chemotherapy is the common and critical limitation for cancer therapy including breast cancer [20]. Although personalized or targeting molecular cancer therapy is more popular in clinic practice up to now, the cytotoxicity chemotherapy for patients with advanced breast cancer is considered as the alternative option. Doxorubicin (DOX) is commonly used chemotherapeutic agents for the treatment of breast cancer [21]. However, chemoresistance often occurs after several circles of therapy. Therefore, finding out a novel strategy to resensitise DOX on drug-resistant cancer cell attracts more attentions in cancer chemotherapy.
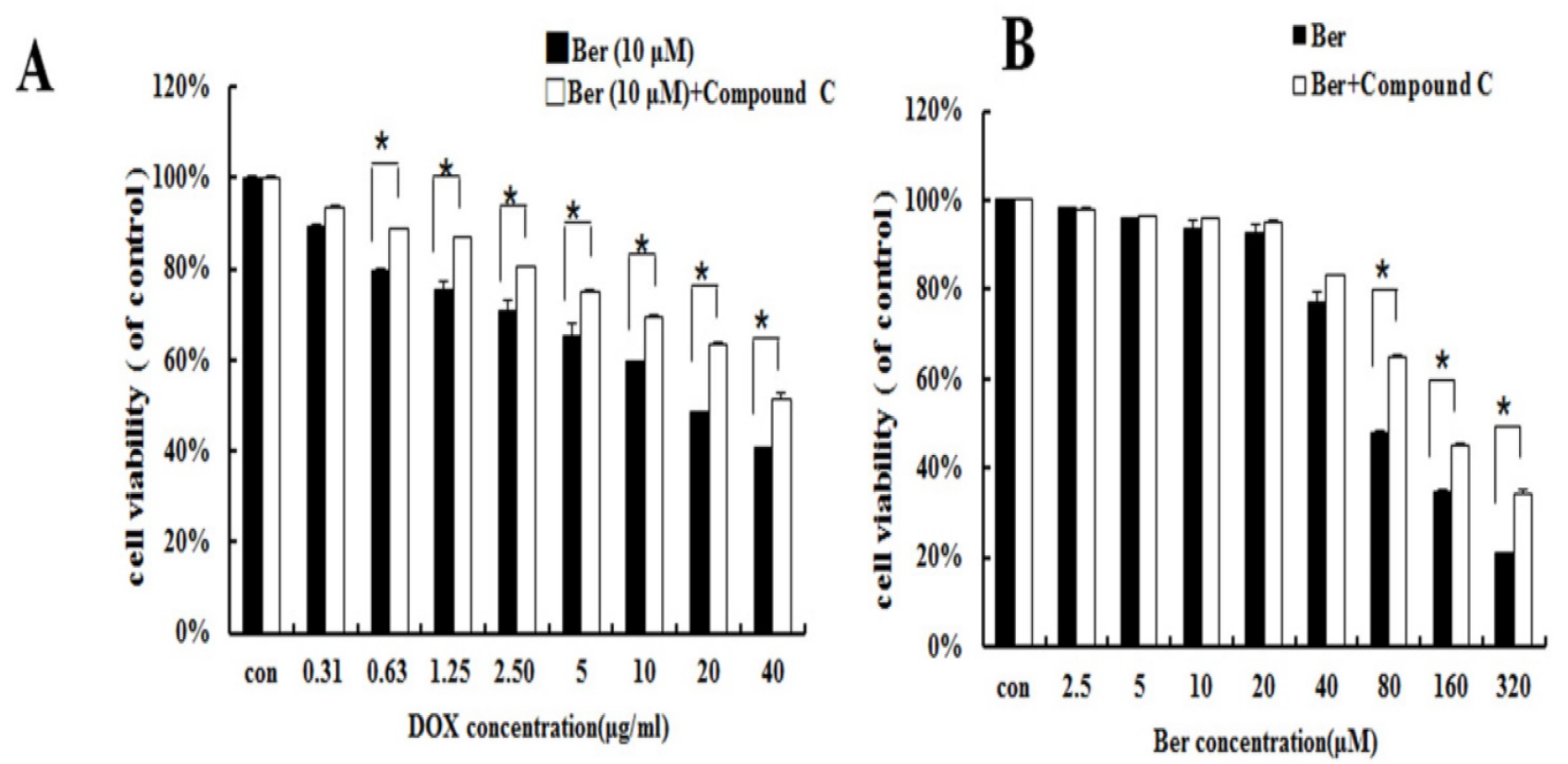

C

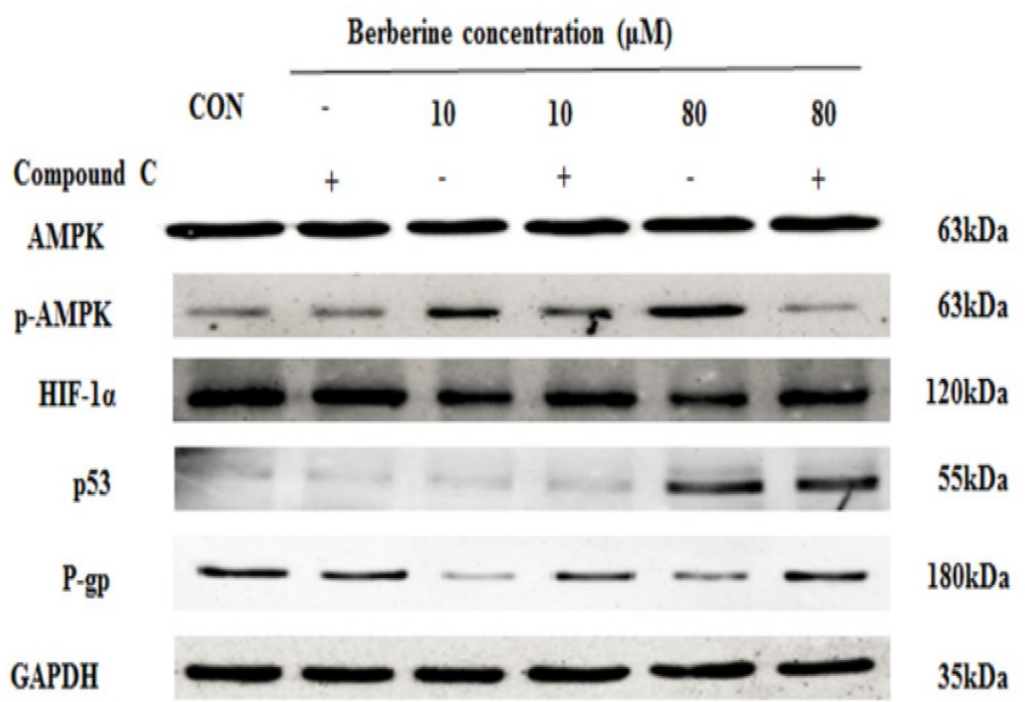

Figure 4. The effect of AMPK on berberine sensitiving drug resistance and inhibiting cell viability. (A) Cell viability in MCF-7/MDR cells after DOX combined with 10 $\mu \mathrm{M}$ berberine treatment, or DOX combined with $10 \mu \mathrm{M}$ berberine and Compound $\mathrm{C}$ treatment. Mean values \pm SD, $* \mathrm{P}<0.05$, MCF-7/MDR cells treated with DOX combined with $10 \mu \mathrm{M}$ berberine for $48 \mathrm{~h}$ vs. MCF-7/MDR cells treated with DOX combined with $10 \mu \mathrm{M}$ berberine and Compound $\mathrm{C}$ for $48 \mathrm{~h}$. (B) Cell viability in MCF-7/MDR cells after berberine treatment or berberine and Compound $C$ treatment. $* \mathrm{P}<0.05$, MCF-7/MDR cells treated with berberine for $48 \mathrm{~h}$ vs. MCF-7/MDR cells treated with berberine and Compound $\mathrm{C}$ for $48 \mathrm{~h}$. (C) AMPK, HIF-1 $\alpha$, P-gp and p53 protein expression after berberine treatment or berberine and Compound $\mathrm{C}$ treatment. Each result was repeated three times. 

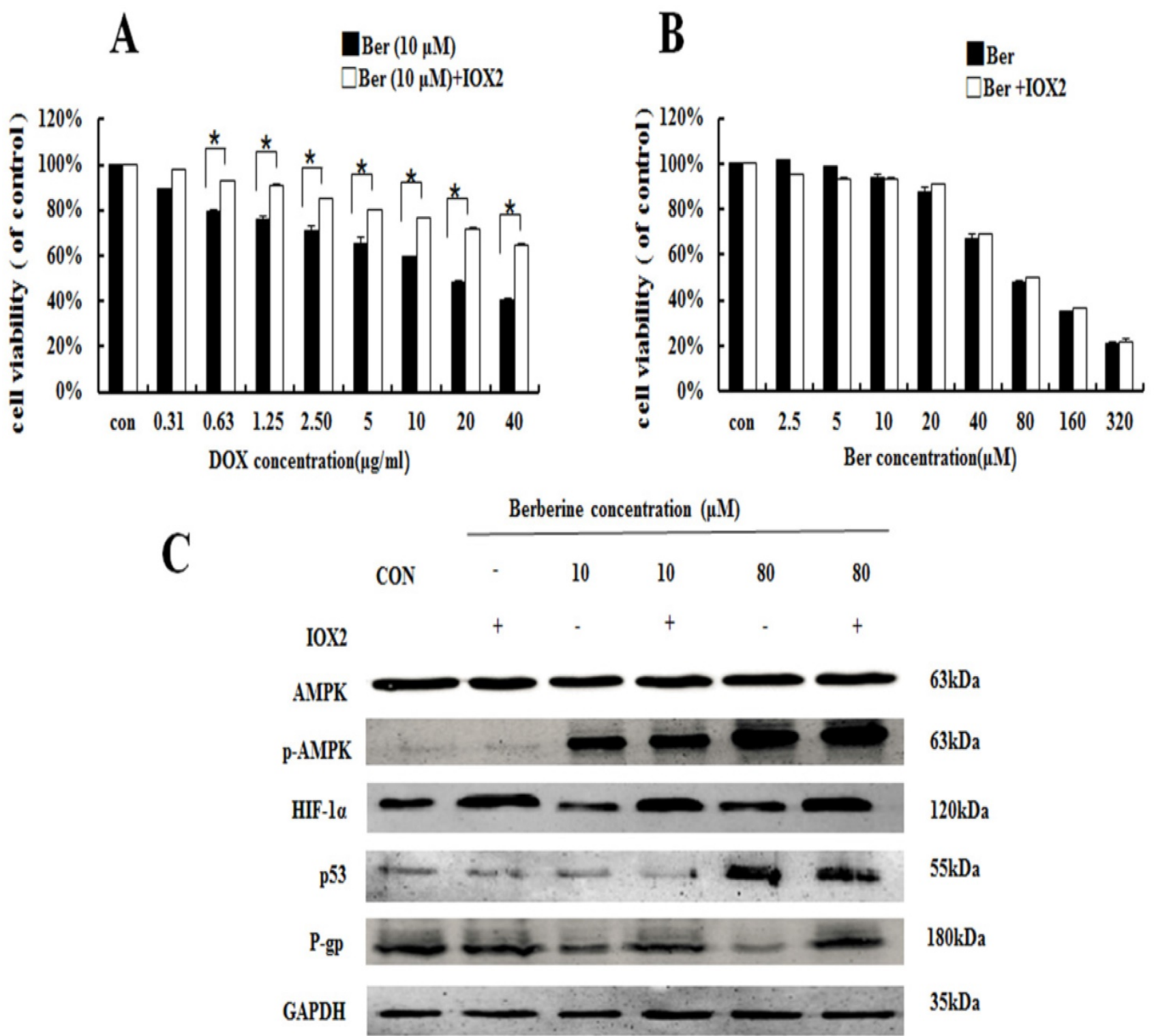

Figure 5. The effect of HIF-1 $\alpha$ on Berberine sensitiving drug resistance and inhibiting cell viability. (A) Cell viability in MCF-7/MDR cells after DOX combined with $10 \mu \mathrm{M}$ berberine treatment or DOX combined with $10 \mu \mathrm{M}$ berberine and IOX2 treatment. $* \mathrm{P}<0.05$, MCF-7/MDR cells treated DOX combined with $10 \mu \mathrm{M}$ berberine for $48 \mathrm{~h}$ vs. MCF-7/MDR cells treated DOX combined with $10 \mu \mathrm{M}$ berberine and IOX2 for $48 \mathrm{~h}$. (B) Cell viability in MCF-7/MDR cells after berberine treatment or berberine and IOX2 treatment. Mean values \pm SD. $* \mathrm{P}<0.05, \mathrm{MCF}-7 / \mathrm{MDR}$ cells treated with berberine for $48 \mathrm{~h}$ vs. MCF-7/MDR cells treated with berberine and IOX 2 for 48 h. (C) AMPK, HIF-1 a, P-gP and p53 protein expression after berberine treatment or berberine-combined IOX 2 treatment. Each result was repeated three times.

Berberine, a traditional chinese drug isolated from Coptischinensis, Hydrastis Canadensis and Berberidaceae, possess multiple function including anti-tumor effect. However, some studies showed that low-dose berberine can enhance radiosensitivity and in colon cancer cells by inhibiting P-gp [16, 17]. As we known that the most prominent mechanism underlying MDR is related with the overexpressed ATP-binding cassette (ABC) transporters [17]. MDR1/P-gp, a member of the ABC transporter family, promotes the excretion of xenobiotic or drug, resulting in the reduction of intracellular concentrations [22]. Our results showed that low-dose berberine inhibited P-gp expression which regulated by the upstream AMPK activation. Energy metabolism change have been shown in the most MDR cells, such as the inhibition complex I and complex IV of the mitochondria respiratory chain, ATP depletion, and decreasing oxygen consumption and glucose consumption, which could be reversed by activation of AMPK to reduce so-called 'Warburg effect' [23]. Furthermore, AMPK pharmacological inhibitor (compound C) increased expression of HIF-1a and P-gp, deteriorating DOX resistance on breast cancer cells, HIF-1a activator weaken the increasing DOX sensitivity with the combination of 
berberine, suggesting that low-dose berberine mechanism of AMPK modulating HIF-1a expression reversed DOX chemoresistance by AMPK-HIF-1a-P-gp signaling pathway. The translational level [13].

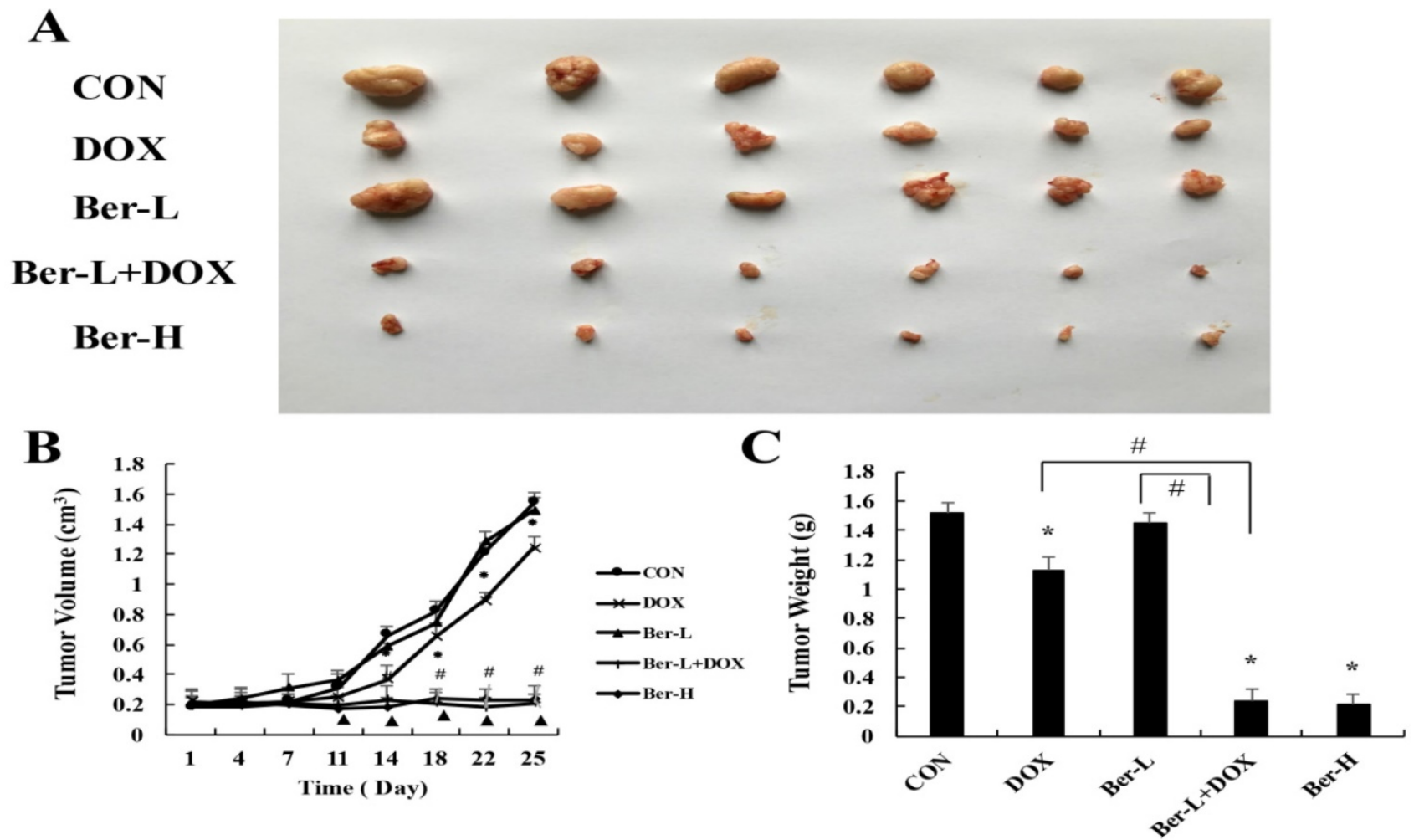

Figure 6. The overcoming of drug resistance effect of berberine in vivo. $(A)$ tumor photographs (B) tumor volume Mean values $\pm S D$, $* P<0.05$, $D O X$ vs. control group. \# $\mathrm{P}<0.05$, Ber-L+DOX vs. control group. $\Delta \mathrm{P}<0.05$, Ber-H vs. control group. (C) tumor weight $* \mathrm{P}<0.05$, mice treated with $\mathrm{DOX}$ or (and) berberine vs. control group, \# $\mathrm{P}<0.05$ Ber-L+DOX vs. DOX or Ber-L.

\section{CON DOX Ber-L Ber-L+DOX Ber-H}

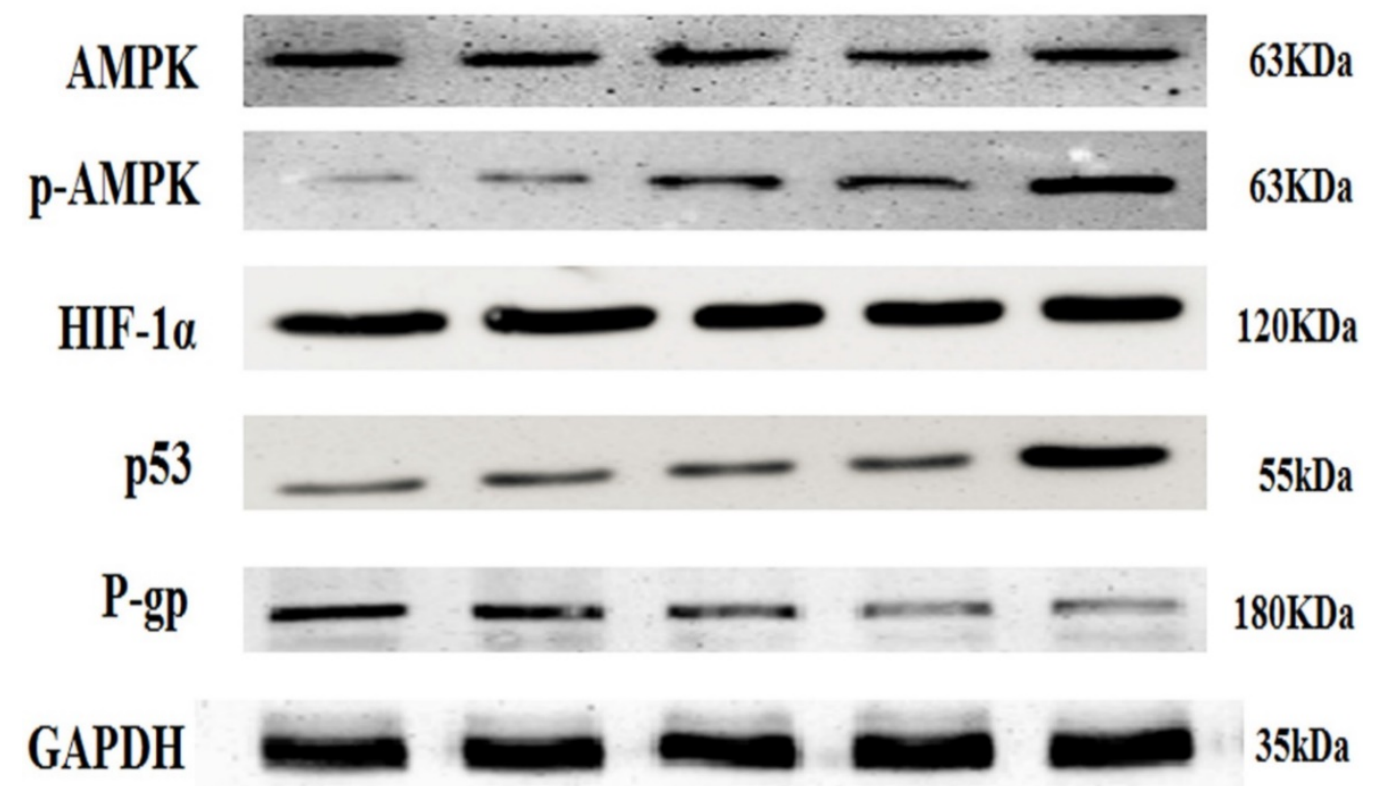

Figure 7. AMPK, p-AMPK, HIF-1 $\alpha$, P-gp and p53 protein expression in MCF-7/MDR xenograft. Each result was repeated three times. 
Our data revealed that high-dose berberine could overcome breast cancer drug resistance by directly inducing apoptosis. p53 is the most commonly mutated tumor suppressor gene, and a lack of functional p53 is associated with an increased risk of the development of drug resistance [24]. Furthermore, it has been reported that the treatment of A549 cells (expressing wild-type p53) are more sensitive than human lung cancer cells H1299 (p53-deficient) after berberine treatment [25, 26]. Our results showed that high-dose berberine could significantly activate p53 rather than the low dose, which was regulated by phosphorylated AMPK [27]. It is reported that AMPK activation is associated with the phosphorylation of p53 at Ser15 and Ser20 [28]. AMPK inhibitor Compound $C$ reduced the p53 expression and decreased apoptosis. HIF-1a expression displayed no dose-dependent manner whether in berberine alone or berberine combined with compound $\mathrm{C}$, indicating that HIF-1a activity was not essential for high-dose berberine-induced apoptosis in MCF-7/MDR cell lines. Moreover, IOX2 did not affect the expression of p53 in $80 \mu \mathrm{M}$ berberine treatment. Consequently, high-dose berberine induced apoptosis by activating the AMPK-p53 pathway with the independence of HIF-1a.

In summary, this work showed that low-dose berberine could enhance DOX sensitivity on drug-resistant breast cancer in vivo and in vitro through the AMPK-HIF-1a-P-gp pathway. High-dose berberine directly induced apoptosis on drug-resistant breast cancer by activating the AMPK-p53 pathway. Our observations shed light on a potentially therapeutic attempt to overcome breast cancer drug resistance.

\section{Acknowledgements}

Prof. Fengying Guan, Wenliang Liu, Yongfei Tan, Fan Yao and Yang Yu are acknowledged for their help in preparing the paper. This work is sponsored by National Natural Science Foundation of China (81201804, 81371681), the Opening Project of State Key Laboratory of Supramolecular Structure and Materials of Jilin University under Grant No. SKLSSM 201504 and 201713, and Undergraduate Innovative Program of Jilin University (2016A79311, 2016B79690). Most of experiments were carried out at Nanomedicine Engineering Laboratory of Jilin Province and Preclinical Pharmacology R\&D Center of Jilin Province.

\section{Competing Interests}

The authors have declared that no competing interest exists.

\section{References}

1. Kovalev AA, Tsvetaeva DA, Grudinskaja TV. Grudinskaja. Role of ABC-cassette transporters (MDR1, MRP1, BCRP) in the development of primary and acquired multiple drug resistance in patients with early and metastatic breast cancer. Exp Oncol.2013; 35: 287-290.

2. Clarke R, Leonessa F, Trock B. Trock.Multidrug resistance/P-glycoprotein and breast cancer: review and meta-analysis. Semin Oncol.2005; 32: S9-15.

3. Slot AJ, Molinski SV, Cole SP. Cole.Mammalian multidrug-resistance proteins (MRPs). Essays Biochem.2011; 50: 179-207.

4. Liberti MV, Locasale JW.The Warburg Effect: How Does it Benefit Cancer Cells? Trends Biochem Sci. 2016; 41: 211-218.

5. Faubert B, Boily G, Izreig S, Griss T, Samborska B, et al. AMPK is a negative regulator of the Warburg effect and suppresses tumor growth in vivo. Cell Metab. 2013;17: 113-124.

6. Martinez-Outschoorn UE, Lin Z, Ko YH, Goldberg AF, Flomenberg N, et al.Understanding the metabolic basis of drug resistance: therapeutic induction of the Warburg effect kills cancer cells. Cell Cycle. 2011; 10: 2521-2528.

7. Bhattacharya B, Mohd Omar MF, Soong R. The Warburg effect and drug resistance. Br J Pharmacol. 2016; 173: 970-979.

8. Ma S, Jia R, Li D, Shen B. Targeting Cellular Metabolism Chemosensitizes the Doxorubicin-Resistant Human Breast Adenocarcinoma Cells. Biomed Res Int. 2015: 453986.

9. Milane L, Ganesh S, Shah S, Duan ZF.Amiji M. Multi-modal strategies for overcoming tumor drug resistance: hypoxia, the Warburg effect, stem cells, and multifunctional nanotechnology. J Control Release. 2011; 155: 237-247.

10. Xue C, Wang $C$, Liu $Q$, Meng $Q$, Sun $H$, et al. Targeting P-glycoprotein expression and cancer cell energy metabolism: combination of metformin and 2-deoxyglucose reverses the multidrug resistance of K562/Dox cells to doxorubicin. Tumor Biol. 2016; 37: 8587-8597.

11. Tavares-Valente D, Baltazar F, Moreira R, Queirós O. Cancer cell bioenergetics and $\mathrm{pH}$ regulation influence breast cancer cell resistance to paclitaxel and doxorubicin. J Bioenerg Biomembr. 2013; 45: 467-475.

12. Hui $G$, Jing $X$, Jianjun $P$, Yantao $H$, Qixiao $J$, et al. Hispidulin inhibits proliferation and enhances chemosensitivity of gallbladder cancer cells by targeting HIF-1a. Exp Cell Res. 2015; 332: 236-246.

13. Harada $K$, Ferdous $T$, Harada $T$, Ueyama $Y$. Metformin in combination with 5 -fluorouracil suppresses tumor growth by inhibiting the Warburg effect in human oral squamous cell carcinoma. Int J Oncol. 2016; 49: 276-284.

14. Kim I, He YY. Targeting the AMP-activated protein kinase for cancer prevention and therapy. Front Oncol. 2013; 3: 175.

15. Lin HL, Liu TY, Wu CW, Chi CW. Berberine modulates expression of mdr1 gene product and the responses of digestive track cancer cells to Paclitaxel. Br J Cancer. 1999; 81: 416-422.

16. Zhang $Q$, Zhang C, Yang X, Yang B, Wang J et al. Berberine inhibits the expression of hypoxia induction factor-1alpha and increases the radiosensitivity of prostate cancer. Diagn Patho. 2014; 9: 1-7.

17. Xi Y, Baixia Y, Jing C, Chi Z, Qu Z, et al. Berberine enhances radiosensitivity of esophageal squamous cancer by targeting HIF-1a in vitro and in vivo. Cancer Biol Ther. 2013; 14: 1068-1073.

18. Kae-Woei L, Sui-Chu Y, Chih-Tai T, Shing-Jong L, Chi-Mei H, et al. Berberine inhibits platelet-derived growth factor-induced growth and migration partly through an AMPK-dependent pathway in vascular smooth muscle cells. Eur J Pharmacol. 2008;590: 343-354.

19. Janina D, Tanja P, Virginia E, Dirk S, Annette S, et al. Impairment of hypoxia-induced HIF-1a signaling in keratinocytes and fibroblasts by sulfur mustard is counteracted by a selective PHD-2 inhibitor. Arch Toxicol. 2016; 90(5): 1141-1150.

20. Olga K, Jody F, James M, Yaroslav I, Volodymyr P. T, et al. Involvement of microRNA-451 in resistance of the MCF-7 breast cancer cells to chemotherapeutic drug doxorubicin. Mol Cancer Ther. 2008; 7(7): 2152-2159.

21. Taylor CW, Dalton WS, Parrish PR, et al. Different mechanisms of decreased drug accumulation in doxorubicin and mitoxantrone resistant variants of the MCF-7 human breast cancer cell line. Br J Cancer.1991; 63(6): 923.

22. Comerford KM, Wallace TJ, Karhausen J, et al. Hypoxia-inducible factor-1-dependent regulation of the multidrug resistance (MDR1) gene. Cancer Res. 2002; 62(12): 3387-3394.

23. Alakhova DY, Rapoport NY, Batrakova EV, Timoshin AA, Li S, et al Differential metabolic responses to pluronic in MDR and non-MDR cells: a novel pathway for chemosensitization of drug resistant cancers. J Control Release. 2010;142(1): 89-100.

24. Aljada A, Mousa SA. Metformin and neoplasia: implications and indications. Pharmacol Ther. 2012; 133: 108-115.

25. Katiyar SK, Meeran SM, Katiyar N, Akhtar S. p53 Cooperates berberine-induced growth inhibition and apoptosis of non-small cell human lung cancer cells in vitro and tumor xenograft growth in vivo. Mol Carcinog. 2009; 48: 24-37.

26. Wang XM, Xiao $\mathrm{H}$, Liu LL, Cheng $\mathrm{D}$, Li XJ, et al. FGF21 represses cerebrovascular aging via improving mitochondrial biogenesis and inhibiting p53 signaling pathway in an AMPK-dependent manner. Exp Cell Res. 2016;346: 147-156.

27. Li P1, Zhao $M$, Parris AB, Feng $X$, Yang X. p53 is required for metformin-induced growth inhibition, senescence and apoptosis in breast cancer cells. Biochem Biophys Res Commun. 2015; 464: 1267-1274. 
28. Yue $\mathrm{P}$, Zheng $\mathrm{W}$, Dan S, Huilin Z Yujing C, et al. CTAB induced mitochondrial apoptosis by activating the AMPK-p53 pathway in hepatocarcinoma cells. Toxicol Res. 2015;4: 1359-1365. 